\title{
TGF $\beta 1$ enhances MAD1 expression and stimulates promoter-bound Pol II phosphorylation: basic functions of C/EBP, SP and SMAD3 transcription factors
}

\author{
Nadine Hein ${ }^{1,2}$, Kan Jiang $^{1,3+}$, Christian Cornelissen ${ }^{1+}$, Bernhard Lüscher $^{1 *}$
}

\begin{abstract}
Background: The MAD1 protein, a member of the MYC/MAX/MAD network of transcriptional regulators, controls cell proliferation, differentiation and apoptosis. MAD1 functions as a transcriptional repressor, one direct target gene being the tumor suppressor PTEN. Repression of this gene is critical to mediate the anti-apoptotic function of MAD1. Under certain conditions it also antagonizes the functions of the oncoprotein MYC. Previous studies have demonstrated that MAD1 expression is controlled by different cytokines and growth factors. Moreover we have recently demonstrated that the MAD1 promoter is controlled by the cytokine granulocyte colony-stimulating factor (G-CSF) through the activation of STAT3, MAP kinases and C/EBP transcription factors.

Results: We observed that in addition to G-CSF, the cytokine transforming growth factor $\beta$ (TGF $\beta 1$ ) rapidly induced the expression of MAD1 mRNA and protein in promyelocytic tumor cells. Moreover we found that C/EBP and SP transcription factors cooperated in regulating the expression of MAD1. This cooperativity was dependent on the respective binding sites in the proximal promoter, with the CCAAT boxes being bound by C/EBP $\alpha / \beta$ heterodimers. Both C/EBP and SP transcription factors bound constitutively to DNA without obvious changes in response to TGF 31 . In addition SMAD3 stimulated the MAD1 reporter, cooperated with C/EBP $\alpha$ and was bound to the core promoter region. Thus SMAD3 appears to be a potential link between TGF $\beta 1$ signaling and C/EBP regulated promoter activity. Moreover TGF $\beta 1$ stimulated the phosphorylation of polymerase II at serine 2 and its progression into the gene body, consistent with enhanced processivity.

Conclusions: Our findings suggest that C/EBP and SP factors provide a platform of transcription factors near the core promoter of the MAD1 gene that participate in mediating signal transduction events emanating from different cytokine receptors. SMAD3, a target of TGF $\beta 1$ signaling, appears to be functionally relevant. We suggest that a key event induced by TGF $\beta 1$ at the MAD1 promoter is the recruitment or activation of cofactors, possibly in complex with $\mathrm{C} / \mathrm{EBP}, \mathrm{SP}$, and SMAD3 transcriptional regulators, that control polymerase activity.
\end{abstract}

\section{Background}

The MYC/MAX/MAD network of transcriptional regulators is essential to control many aspects of cell physiology [1]. MYC was originally identified as oncogene in several different chicken retroviruses. Subsequently the three human MYC genes, MYC, MYCN and MYCL

\footnotetext{
* Correspondence: luescher@rwth-aachen.de

+ Contributed equally

'Institute of Biochemistry and Molecular Biology, Medical School, RWTH

Aachen University, 52057 Aachen, Germany

Full list of author information is available at the end of the article
}

were found deregulated in the large majority of human tumors [2]. The potent capacity of MYC to transform cells has also been supported by a large number of studies in both primary cells and established cell lines and in animal models. Central to the ability to transform cells is MYC's function as transcriptional regulator in controlling the expression of a large number of target genes. This explains, at least in part, the broad biological activities associated of MYC [3,4]. The functions of $\mathrm{MYC}$ in gene expression control depend largely on its 
interaction with MAX, the central component of the MYC/MAX/MAD network.

MAD proteins are alternative binding partners of MAX [5]. Six different MAD proteins have been identified. MAD1-4 are highly related, while MNT and MGA are considerably larger multi-domain proteins. Similar to $\mathrm{MYC}$, the MAD proteins are transcriptional regulators, with MAD1-4 primarily described as repressors. Unlike MYC proteins, the MADs have not been linked to human diseases, in particular they appear not to be tumor suppressors as one might have expected. For MAD1-4 the reason for their apparent lack to function as tumor suppressors may be in part due to their broad and overlapping expression pattern, suggesting that more than one MAD family member would need to be inactivated in tumors [5]. In addition, MAD proteins, best studied for MAD1, have anti-apoptotic activity and thus may antagonize the pro-apoptotic functions of MYC proteins [6-8]. This activity of MAD proteins may be indispensable for tumor development. In support, one of the few MAD1 target genes that has been identified is the tumor suppressor gene PTEN [8]. MAD1, which functions primarily as a transcriptional repressor by recruiting histone deacetylase-containing complexes [9-12], represses the PTEN promoter directly [8]. This contributes to the anti-apoptotic phenotype elicited by MAD1. The analysis of granulocytes from mice lacking Mad1 revealed increased sensitivity to pro-apoptotic conditions [6], further supporting the view that MAD1 protects cells from different apoptotic stimuli.

In addition to the anti-apoptotic function, MAD1 has been suggested to control proliferation and differentiation antagonistically to MYC [5]. Indeed the unscheduled expression of MAD1 interferes with cell proliferation and the lack of Mad1 results in a differentiation defect of granulocytes [6,7,13-15]. During the studies to elucidate the functions of MAD1 in proliferation and differentiation, it had been noted early on that the expression of the $M A D 1$ gene is highly regulated, generally reciprocal to the regulation of $M Y C$ genes [5]. Moreover MAD1 expression is directly downregulated by MYC (NH and BL, unpublished observations). In particular several differentiation inducing agents, including transforming growth factor $\beta$ (TGF $\beta$ ), retinoic acid, and granulocyte-colony stimulating factor (G-CSF), were identified as stimulators of $M A D 1$ expression [16-20]. These findings led us to address the question how the $M A D 1$ promoter is organized and how signals of these differentiation factors control gene expression. The $M A D 1$ promoter contains a CpG island as part of a roughly $400 \mathrm{bp}$ proximal promoter region highly conserved between humans and rodents [17]. This region is responsive to G-CSF, integrating signals transduced from the G-CSF receptor by STAT3 and by the RAS-
RAF-ERK pathway. This regulation of the $M A D 1$ promoter by G-CSF is in agreement with the described role of this cytokine and of Mad1 in the control of granulocyte differentiation and survival [6].

Cytokines of the TGF $\beta$ family have broad activities in controlling cell physiology, including proliferation, differentiation and survival [21-23]. TGF $\beta$ signals through TGF $\beta$ type II and I receptors with Ser/Thr kinase activity, thereby activating SMAD proteins, in particular SMAD2 and 3 in combination with SMAD4. These proteins translocate to the cell nucleus and form complexes with additional molecules to control the expression of target genes [24]. We have shown previously that the phorbol ester TPA and TGF $\beta$ activate the expression of MAD1 in U937 and in $\mathrm{HaCaT}$ keratinocytes, respectively $[18,19]$. In both systems a substantial increase in mRNA expression was observed by $90 \mathrm{~min}$, suggesting that the induction was direct. Different kinetics of $M A D 1$ induction were observed in a clone of U937 promyelocytes that stably express a viral version of MYC (U937-myc6). In these cells a weak induction was observed in response to TGF $\beta$ by $8 \mathrm{hrs}$, possibly as a result of constitutive MYC expression [20]. To understand in more detail how TGF $\beta 1$ regulates $M A D 1$ gene expression, we addressed how this cytokine affects $M A D 1$ promoter activity. It appears that TGF $\beta 1$ stimulates $M A D 1$ through elements proximal to the core promoter.

\section{Results and Discussion \\ Rapid activation of MAD1 by TGF $\beta$}

During cell proliferation and differentiation, the MAD1 gene is regulated by multiple signaling pathways. One of the regulatory cytokines is TGF $\beta 1$, which is known to induce MAD1 in keratinocytes and in U937-myc6 promyelocytes $[19,20]$. To further evaluate the role of TGF $\beta 1$ in regulating $M A D 1$, we performed time course experiments. TGF $\beta 1$ rapidly activated MAD 1 mRNA expression in U937 cells (Figure 1A). In parallel, MAD1 protein became detectable within 4 hrs of TGF $\beta 1$ stimulation (Figure 1B). Thus the induction of MAD1 protein follows closely the up-regulation seen at the mRNA level. The induction of $M A D 1$ expression was dependent on the TGF $\beta$ receptor (TGF $\beta R$ ) since the TGF $\beta$ RI inhibitor SB505124 blocked MAD1 activation (Figure 1C). Moreover inhibition of the MAPK p38 resulted in a partial inhibition of $M A D 1$ expression in response to TGF $\beta 1$, whereas the inhibition of JNK or ERK kinases did not repress $M A D 1$ expression (Figure $1 C$ ). The activities of the inhibitors were verified by analyzing the phosphorylation of the relevant kinases (data not shown). These findings indicate that TGF $\beta 1$ may signal by different pathways to the $M A D 1$ promoter. Indeed the TGF $\beta$ is known to activate several different 


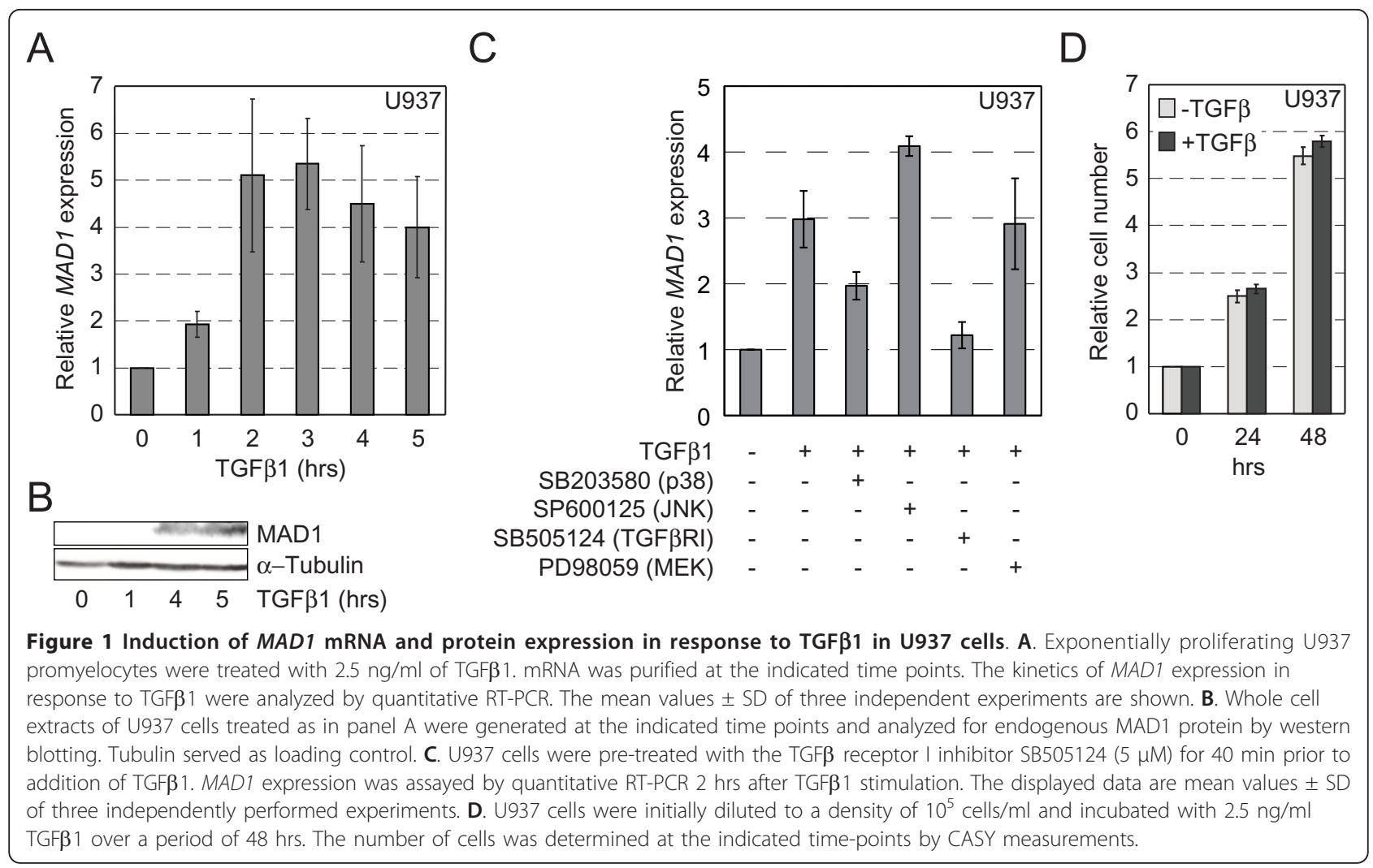

signaling cascades in addition to SMAD transcription factors, including different MAP kinases and the PI3KAKT pathway [25].

MAD1 has been demonstrated to interfere with cell proliferation in some cell types $[7,14]$. Therefore we measured whether the induction of MAD1 by TGF $\beta 1$ affected the proliferation of U937 tumor cells. However the early TGF $\beta 1$-stimulated induction of MAD1 was not sufficient to block U937 proliferation (Figure 1D), similar to the observations made in U937-myc6 cells [20]. Our findings suggest that tumor cells like U937 have the possibility to bypass at least transiently the repressive function of MAD1 in cell proliferation.

\section{$\mathrm{C} / \mathrm{EBP} \alpha / \beta$ heterodimers bind constitutively to the MAD1 promoter}

The MAD1 promoter does not contain any obvious SMAD binding sites in the proximal region. Indeed a recent study suggested that SMAD2/3 stimulate MAD1 expression independent of SMAD4, possibly through an indirect mechansism [26]. Moreover it has been found that SMAD proteins may interact with C/EBP transcription factors to control gene expression [27]. Since we have shown previously that $\mathrm{C} / \mathrm{EBPs}$ control the transcription of $M A D 1$ in response to the cytokine G-CSF in RK13 rabbit epithelial cells [17], we addressed the role of C/EBP transcription factors in human cells. Transient transfection experiments in HeLa cells demonstrated that $\mathrm{C} / \mathrm{EBP} \alpha$ and $\beta$, and to a lesser extend $\mathrm{C} / \mathrm{EBP} \varepsilon$, were able to stimulate -1282 to +248 and -184 to +248 (relative to the major transcriptional start site) $M A D 1$ promoter reporter gene constructs (Figure 2A-C). Moreover knockdown of C/ EBP $\beta$ reduced $M A D 1$ promoter reporter gene activity, suggesting that its expression is controlled by endogenous $\mathrm{C} / \mathrm{EBP} \beta$ (Figure 2D and 2E). This appears to be a direct effect since the mutation of the two CCAAT box-like sequences in the promoter proximal region affected the sensitivity to $\mathrm{C} / \mathrm{EBP} \beta$ (Figure $2 \mathrm{~A}$ ). Deletion of box 1 reduced, while deletion of either box 2 or both elements together eliminated promoter activity in response to $\mathrm{C} /$ EBP $\beta$ (Figure 2F). Together these findings demonstrate that, similar to the observations in RK13 cells, C/EBPs also control MAD1 expression in human cells.

To address whether TGF $\beta 1$ might affect C/EBP binding to the $M A D 1$ promoter, ChIP experiments were performed. Specific C/EBP $\beta$ binding to the core-promoter region was observed, whereas only weak interaction with a more distal promoter region could be detected (Figure 3A). C/EBP $\beta$ was found at the $M A D 1$ promoter prior to TGF $\beta 1$ signaling (Figure $3 \mathrm{~A}$ ). Stimulation by TGF $\beta 1$ did not result in altered binding. Thus C/EBP proteins interact with the promoter independent of 


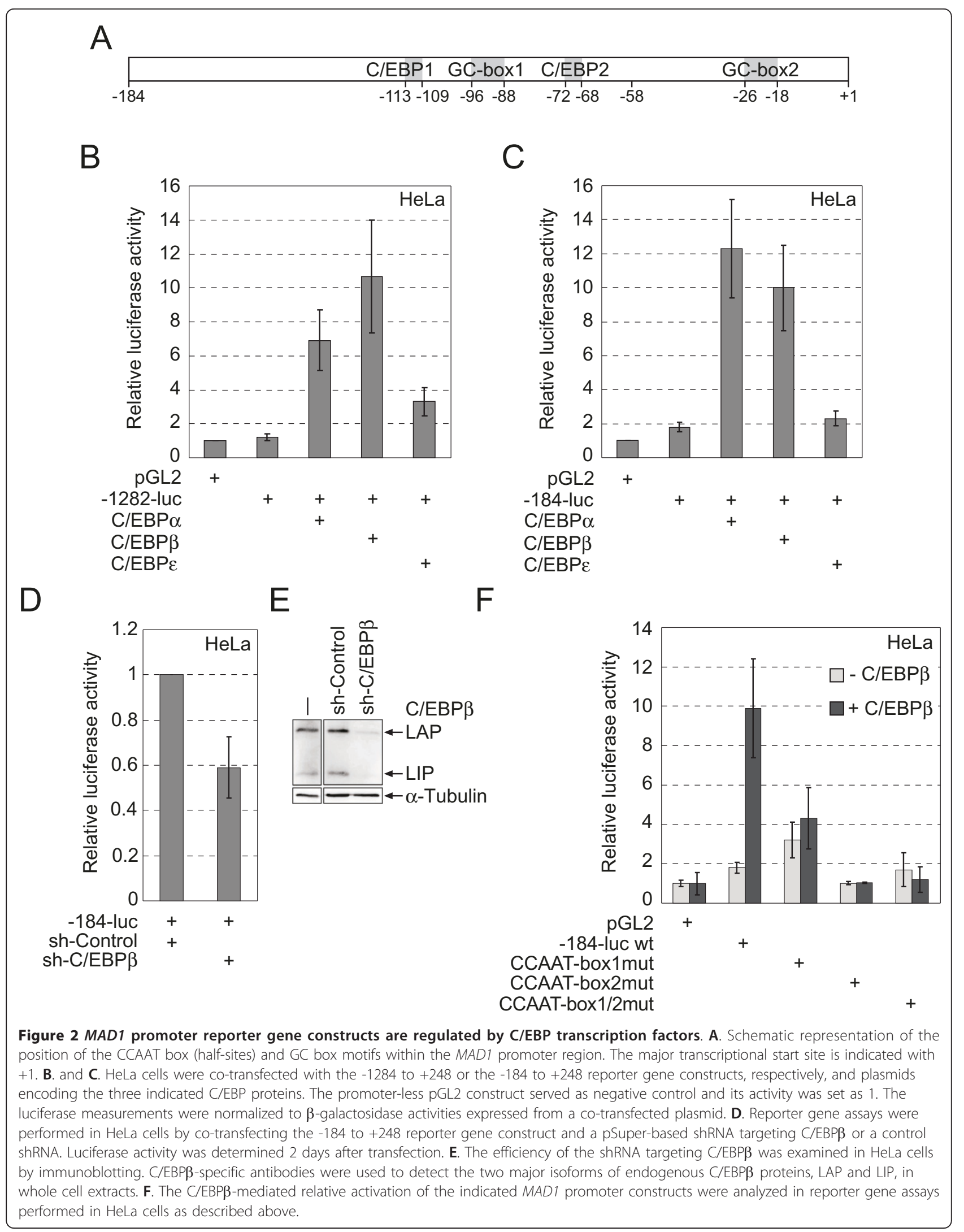


A
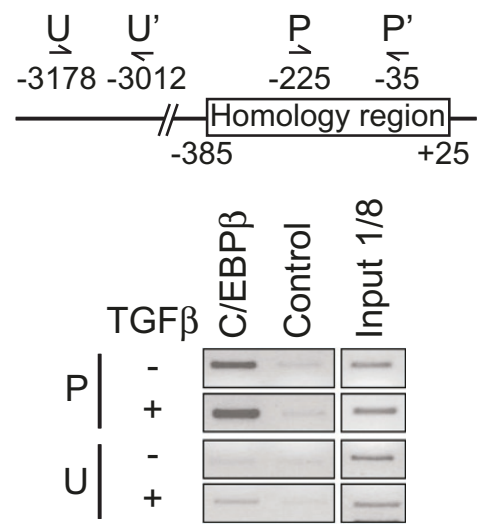

U937

C
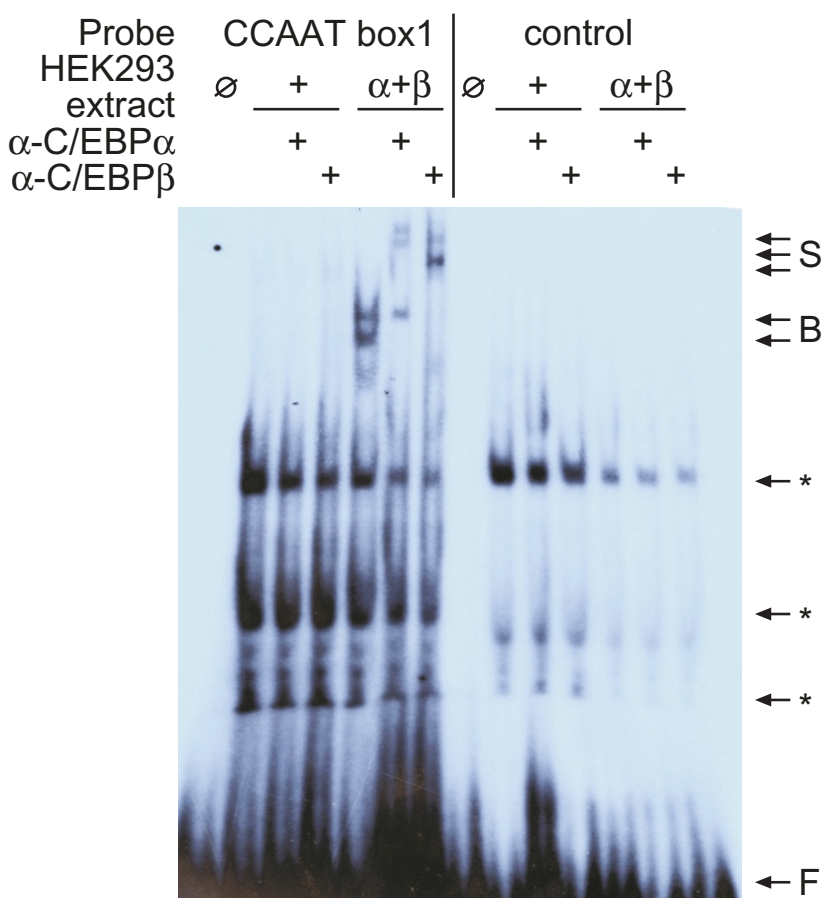

\section{Probe CCAAT box1 NE-CCAAT}

HEK293

extract

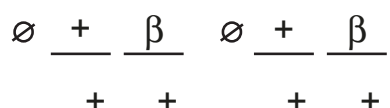

$\alpha-\mathrm{C} / \mathrm{EBP} \beta$
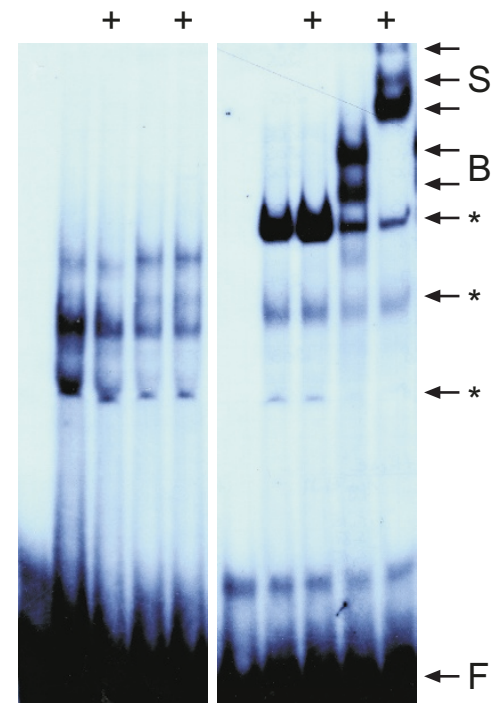

D

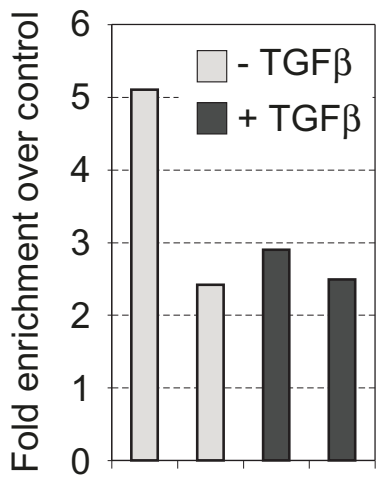

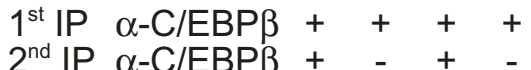

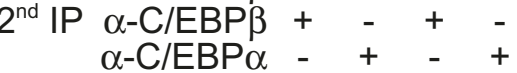

Figure 3 C/EBP $\beta$ binds to the chromatin embedded MAD1 promoter in cells. A. Schematic presentation of the MAD1 promoter relative to the major transcriptional start site with the homology region as defined in [17]. The positions of primer sets used for ChIP PCR are given (upper panel). U937 cells were used in ChIP assays to investigate the binding of C/EBP $\beta$ to the MAD1 promoter in response to TGF $\beta 1$. The cells were treated with $2.5 \mathrm{ng} / \mathrm{ml}$ TGF $\beta 1$ for 1.5 hrs prior to crosslinking and immunoprecipitation, and the purified DNA was analyzed by PCR with the indicated primers. The displayed experiment is representative of three independent experiments with similar outcome. B. C/EBP $\beta$ was expressed in HEK293 cells. Whole cell extracts were generated and incubated with $\left[{ }^{32} \mathrm{P}\right]$-radiolabelled CCAAT box1 oligonucleotids derived from the MAD1 or the neutrophil elastase promoter (NE-CCAAT). Supershift experiments with C/EBP $\beta$ specific antibodies are indicated. The complexes were analyzed by EMSA and detected by autoradiography. $\varnothing$, indicates lanes without cell extracts; + , whole cell extracts of control transfected HEK293 cells; $\beta$, whole cell extracts of HEK293 cells transiently expressing C/EBP $\beta$. C. The C/EBP $\alpha / \beta$ heterodimer DNA-binding activity to CCAAT box1 was determined by EMSA. HEK293 cell extracts overexpressing C/EBP $\alpha$ and C/EBP $\beta$ were generated as in panel B and incubated with radiolabelled CCAAT box1. Supershift experiments were performed with C/EBP $\alpha$ - or C/EBP $\beta$-specific antibody. For control an irrelevant oligonucleotide was used. D. Re-ChIP experiment using C/EBP $\alpha$ - and C/EBP $\beta$-specific antibodies in U937 cells treated with or without TGF $\beta 1$ for 1.5 hrs. The first immunoprecipitation was performed with antibodies specific for C/EBP $\beta$. The protein-DNA complexes were then released and subjected to a second immunoprecipitation using C/EBP $\alpha$ or C/EBP $\beta$ specific antibodies. The isolated DNA was analyzed by quantitative PCR with the primer set $\mathrm{P}$ (panel A) amplifying a portion of the homology region of the MAD1 promoter. The signal intensities obtained with the specific immunoprecipitations were normalized to samples generated with control antibodies. For all panels one representative of typically at least three independent experiments are shown. 
TGF $\beta 1$ signaling. The binding of $\mathrm{C} / \mathrm{EBP}$ proteins to the CCAAT box motifs, both appear only to be half-sites [17], was further evaluated using electrophoretic mobility shift assays (EMSA). Neither of the two half-sites (i. e. CCAAT box1 and CCAAT box2) was bound by $\mathrm{C} /$ $\mathrm{EBP} \alpha$ or $\mathrm{C} / \mathrm{EBP} \beta$ homodimers alone when expressed in HEK293 cells (Figure 3B and data not shown). For control efficient and specific binding of $\mathrm{C} / \mathrm{EBP} \beta$ and $\mathrm{C} /$ $\mathrm{EBP} \alpha$ to a CCAAT box of the neutrophil elastase gene was measurable, as reported previously [28] (Figure 3B and data not shown). Since the findings using ChIP and EMSA were contradictory, we expanded the EMSA experiments by evaluating the binding of $\mathrm{C} / \mathrm{EBP} \alpha / \beta$ heterodimers. In contrast to the homodimers, the heterodimeric $\mathrm{C} / \mathrm{EBP}$ complexes interacted with the CCAAT box1 (Figure 3C) and less well with CCAAT box2 (data not shown). The presence of a heterodimeric complex at CCAAT box 1 was verified using $\mathrm{C} / \mathrm{EBP} \alpha$ and $\beta$ specific antibodies. Both antibodies were able to supershift the complexes observed, further validating that $\mathrm{C} / \mathrm{EBP} \alpha$ / $\beta$ heterodimers were able to bind to the $M A D 1$ promoter. To address whether the chromatin embedded $M A D 1$ promoter was bound by $\mathrm{C} / \mathrm{EBP} \alpha / \beta$ heterodimers, re-ChIP experiments were performed by immunoprecipitating first chromatin-bound $C / E B P \beta$. The bound material was released and re-immunoprecipitated with antibodies specific for either $\mathrm{C} / \mathrm{EBP} \alpha$ or $\mathrm{C} / \mathrm{EBP} \beta$ (second immunoprecipitation) in comparison to a control (Figure 3D). The specific signals obtained with both $\mathrm{C} /$ EBP antibodies suggested that indeed the $M A D 1$ promoter was occupied by $\mathrm{C} / \mathrm{EBP} \alpha / \beta$ heterodimers. Again this was largely independent of TGF $\beta$ signaling (Figure $3 \mathrm{D}$ ).

\section{SP transcription factors bind to the MAD1 promoter independent of TGF $\beta$ signaling}

In addition to CCAAT boxes, the proximal promoter region of the $M A D 1$ gene contains 2 prominent GC boxes (Figure $2 \mathrm{~A}$ ). To test whether SP proteins can bind to either of these two GC boxes, we performed EMSA and ChIP experiments. Prominent binding to an oligonucleotide spanning GC box1, which is flanked by the two CCAAT boxes, was observed in EMSA experiments using U937 cell extracts (Figure 4A). Binding to GC box2 was weaker (data not shown). Supershift experiments using specific antisera indicated that both SP1 and SP3 proteins bind to GC box1 (Figure 4A). Moreover both proteins bound constitutively to the chromatin embedded proximal $M A D 1$ promoter that contains GC box 1 and no change in response to TGF $\beta 1$ was measurable (Figure $4 \mathrm{~B}$ and data not shown). Similarly the binding of SP1 and SP3 to the MAD1 promoter was not affected by G-CSF (data not shown), indicating that these transcription factors as well as C/EBP proteins are constitutively interacting with the $M A D 1$ promoter.

\section{C/EBP and SP transcription factors cooperate in stimulating the MAD1 promoter}

Since the CCAAT and GC boxes are in close proximity within the $M A D 1$ promoter (Figure 2A), we addressed whether SP1 and C/EBP $\beta$ were able to cooperate on $M A D 1$ reporter gene constructs. While SP1 alone had no effect on the expression of the reporter gene, it substantially stimulated C/EBP $\beta$-dependent expression (Figure 5A). This observation was further validated by expressing a dominant negative form of SP1 (SP1dn), which lacks the transactivation domain. SP1dn repressed efficiently $\mathrm{C} / \mathrm{EBP} \beta$-induced $M A D 1$ promoter reporter gene expression (Figure $5 \mathrm{~B}$ ). The cooperative effect of SP1 and C/EBP $\beta$ was dependent on the GC and CCAAT boxes (Figure 5C and 5D). Together these findings suggest that SP and C/EBP proteins bind to the proximal $M A D 1$ promoter and cooperate in activating the $M A D 1$ promoter.

\section{SMAD3 interacts with and activates the MAD1 promoter dependent on C/EBP and SP binding sites}

Next we evaluated whether SMAD proteins are involved in activating the $M A D 1$ promoter by using the -1282 to +248 MAD1 promoter reporter gene construct. This reporter was stimulated by a combination of SMAD2, 3, and 4 but the activity of these factors was not enhanced by coexpressing a constitutive active TGF $\beta$ RI (TGF $\beta$ Rca) (Figure 6A). All these constructs however were active since a SMAD binding element reporter (SBE-luc) was strongly activated by SMADs and TGF $\beta$ Rca (Figure 6B and $6 \mathrm{C}$ ). In the absence of exogenous SMAD proteins the TGF $\beta$ Rca was unable to significantly activate $M A D 1$ promoter reporter constructs (Figure 6D). We further evaluated which SMAD protein(s) stimulated the MAD1 promoter reporter. We found by testing all combinations that only SMAD3 was stimulatory (data not shown). The SMAD3 responsive region was mapped to the promoter fragment that contains the two C/EBP half sites and one SP binding site, i.e. GC box1 (Figure 6E, for the positions of the binding sites see Figure $2 \mathrm{~A}$ ). These response elements appeared to be relevant because mutation of these sites in a reporter containing the -184 to $-58 M A D 1$ promoter fragment upstream of the minimal thymidine kinase promoter (minTK) resulted in almost complete loss of SMAD3 responsiveness (Figure 6F). Consistent with this, $\mathrm{C} / \mathrm{EBP} \alpha$ and SMAD3 cooperated on the -184 MAD1 promoter reporter (Figure 6G). Finally we addressed whether SMAD3 interacted with the $M A D 1$ promoter. Indeed we found that SMAD3 was bound to the MAD1 promoter but not to an irrelevant promoter (MYOD1) (Figure 6F). However stimulation of the U937 cells with TGF $\beta$ did not alter significantly the interaction of SMAD3 with the promoter. Together these findings demonstrate that 


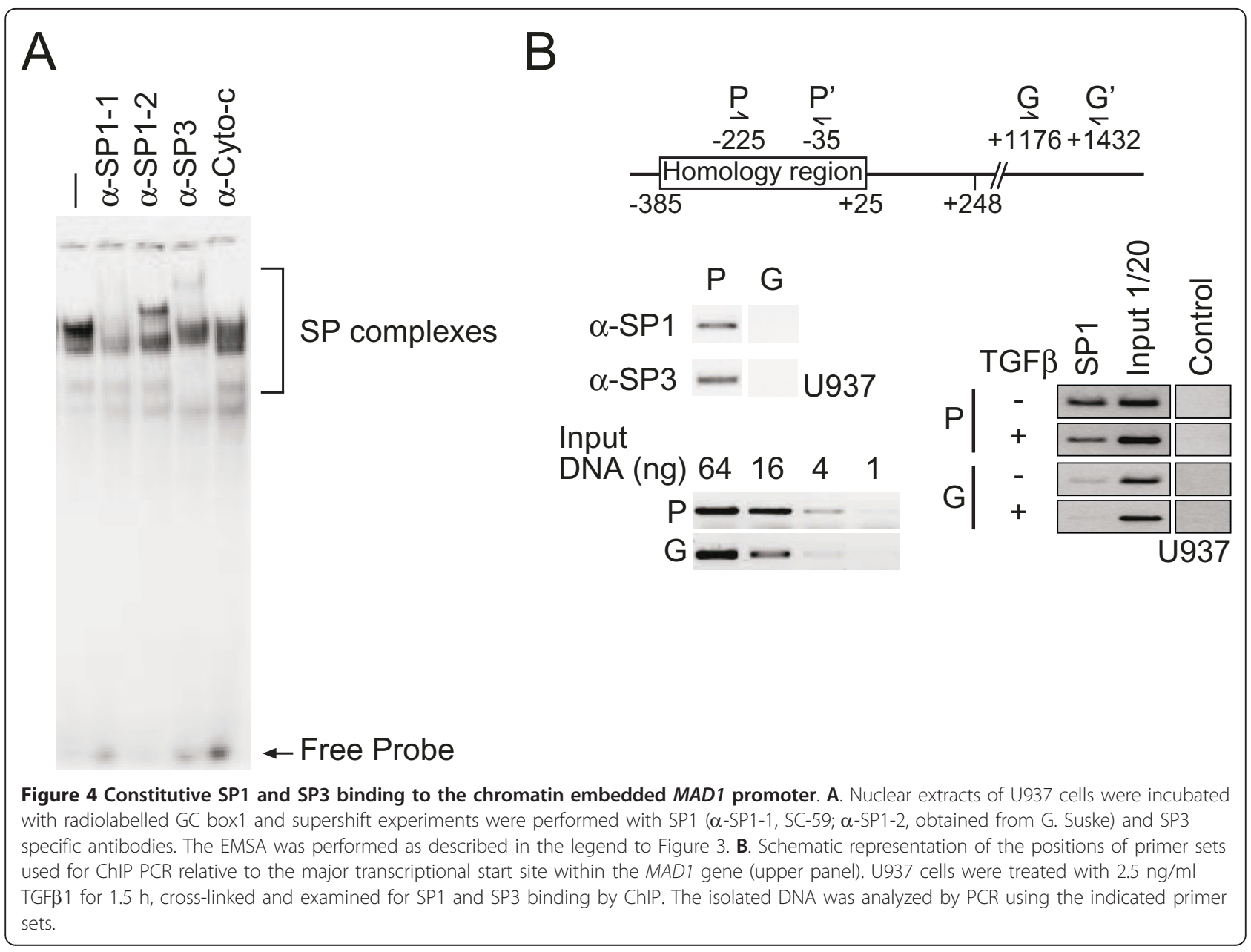

SMAD3 functions as an activating transcription factor for the MAD1 promoter. The lack of regulation by coexpressing SMAD3 with TGF $\beta$ Rca as measured by reporter gene assays may be due to insufficient chromatin formation on the transfected DNA and/or additional important signaling compounds are missing.

\section{TGF $\beta 1$ stimulates Ser2 phosphorylation of Pol II}

To further evaluate how the MAD1 promoter is activated, we analyzed acetylation of histone $\mathrm{H} 3(\mathrm{H} 3 \mathrm{ac})$ and trimethylation at Lys 4 of histone H3 (H3K4me3) before and after TGF $\beta 1$ stimulation. Both are marks for active promoters. We observed H3ac throughout the locus and H3K4me3 at the promoter, however, none of these marks was significantly modified by TGF $\beta 1$ stimulation (Figure 7A-C). These findings suggest that the MAD1 promoter is in an open configuration, similar to what has been observed recently for many promoters of regulated genes [29-31]. This is supported by our previous studies using nucleosomal mapping demonstrating open chromatin at the MAD1 proximal promoter [17]. Consistent with an open configuration is our observation that polymerase II (Pol II) occupied the MAD1 promoter constitutively (Figure 7D). Pol II was also detected in the gene body, where its binding increased in response to TGF $\beta 1$ treatment (Figure 7D). A key step in activating transcription is the differential phosphorylation of Pol II $[32,33]$. It is phosphorylated at Ser-5 of its Cterminal domain (CTD), a modification that defines a preactivation state. Upon stimulation, Pol II becomes phosphorylated at Ser-2 of the CTD, which coincides with elongating polymerase. Therefore we addressed whether phosphorylation at Ser-5 and Ser-2 was altered in response to TGF $\beta 1$. Indeed we observed an increase in Ser-2 phosphorylation upon TGF $\beta 1$ stimulation and a concomitant decrease of Ser-5 phosphorylation of Pol II both at the promoter and in the gene body (Figure 7D). Thus TGF $\beta 1$ regulates Pol II phosphorylation and activity.

\section{Conclusions}

We observed that C/EBP and SP transcription factors bind constitutively to the proximal MAD1 promoter. In addition SMAD3, a factor typically activated by TGF $\beta$ 


\section{A}

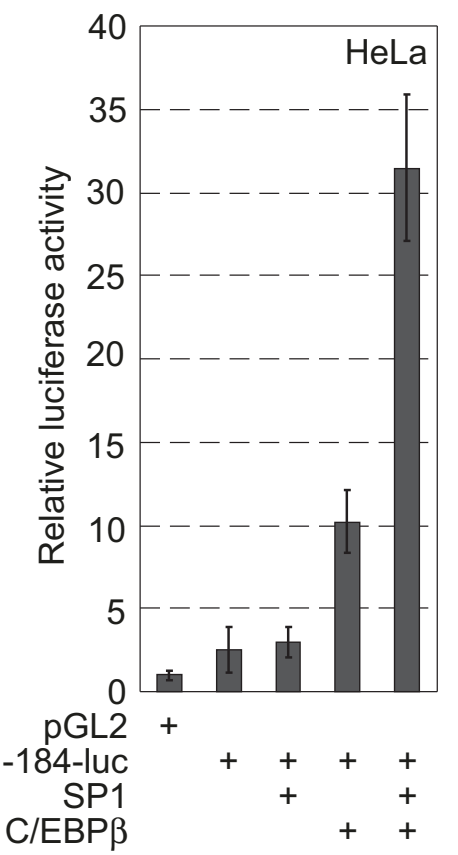

B

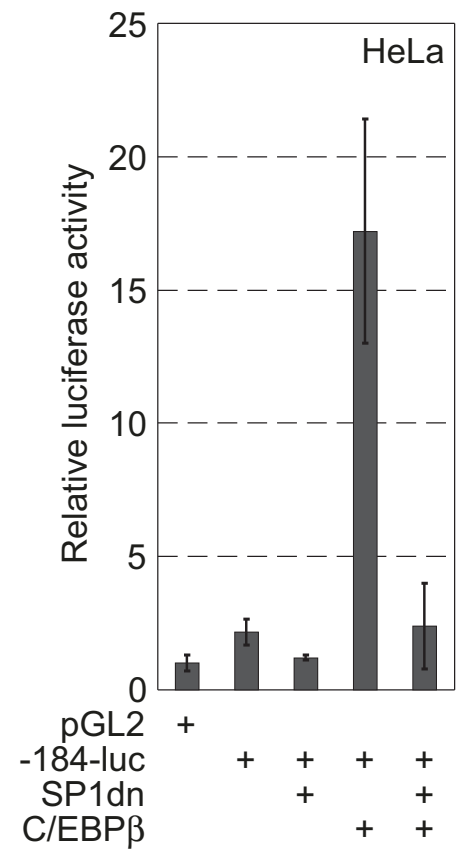

C

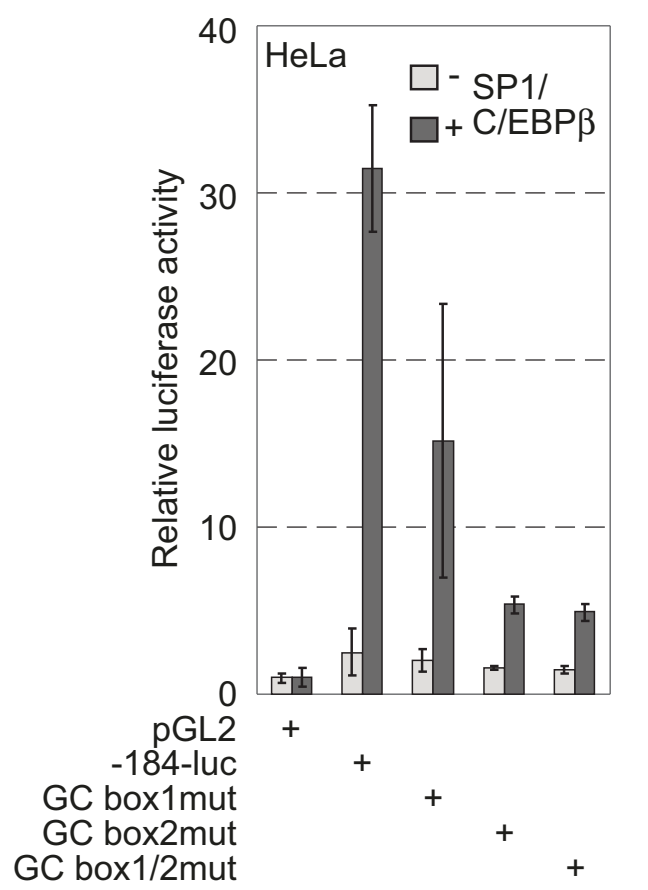

D

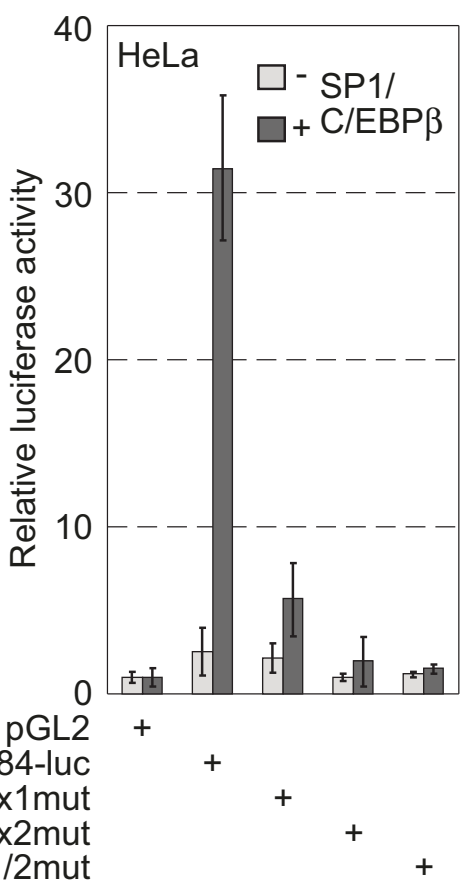

Figure 5 SP1 and C/EBP $\beta$ cooperate in MAD1 promoter reporter gene activation. A. HeLa cells were co-transfected with the -184 to +248 reporter gene construct and C/EBP $\beta$ and/or SP1 expression vectors as indicated. B. A dominant negative SP1 mutant (SP1dn) was co-expressed with C/EBP $\beta$ in HeLa cells and the activity of the -184 to +248 reporter gene construct was determined. C. and $\mathbf{D}$. HeLa cells were transiently transfected with the indicated expression plasmids and the -184 to +248 reporter gene construct or reporter constructs with the indicated mutations in the identified response elements. 


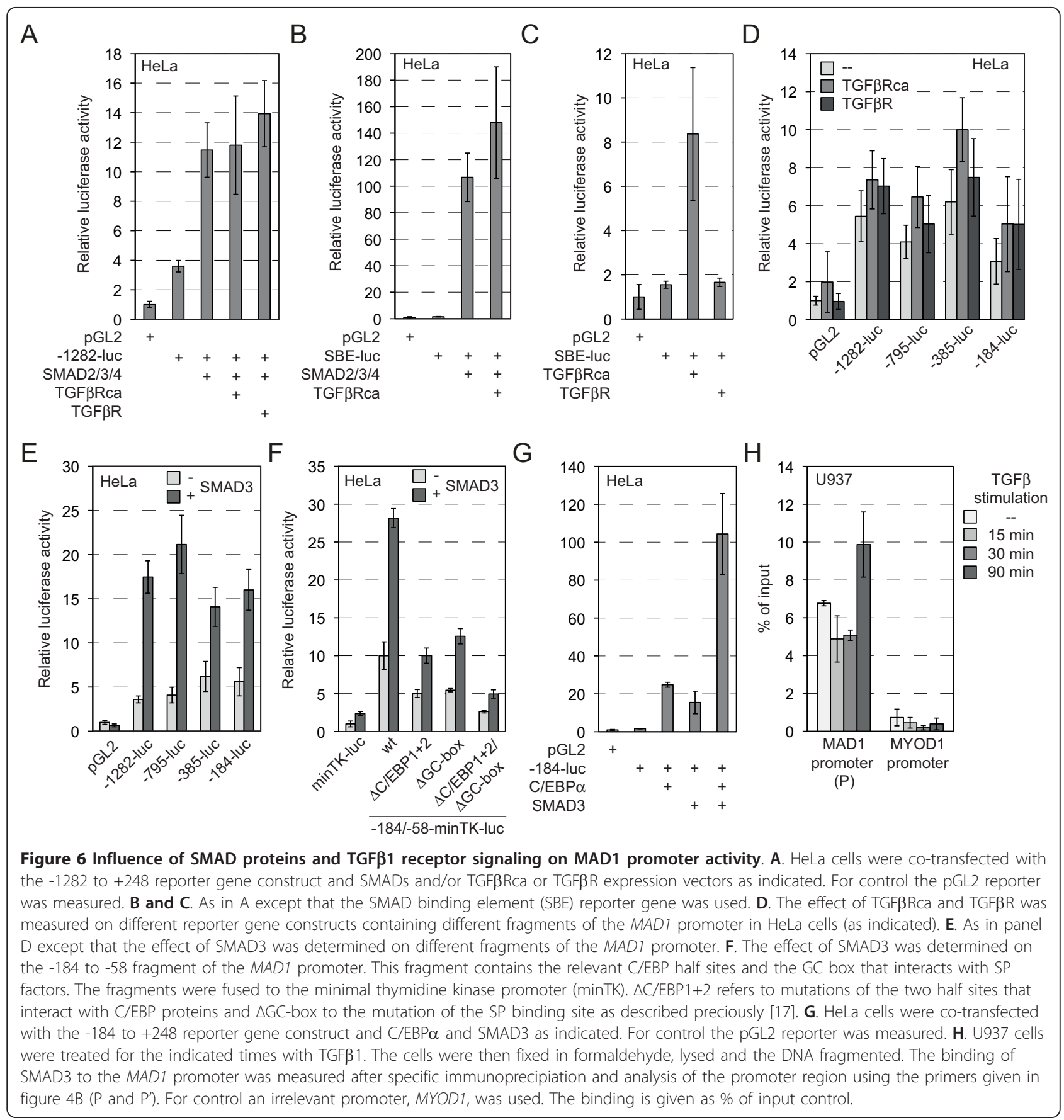

signaling, also was found constitutively on the MAD1 promoter, despite the fact that no obvious binding sites for SMAD proteins are found. While the GC boxes are consensus binding sites for SP1, the proposed CCAAT boxes are deviating considerably from C/EBP consensus sequences. In fact, both elements that were identified functionally, represent only half sites [17]. Consistent with this interpretation, these DNA elements do not bind efficiently C/EBP homodimers in EMSA experiments in vitro. Surprisingly substantial binding was only measurable with $\mathrm{C} / \mathrm{EBP} \alpha / \beta$ heterodimers in these EMSA experiments. Nevertheless both factors were able to stimulate $M A D 1$ promoter reporter genes. We did however not observe a strong synergistic activation by the two proteins, possibly due to abundant endogenous C/EBP factors (data not shown). We suggest that C/EBP and SP transcription factors form a platform for incoming signals as exemplified by G-CSF [17] and possibly TGF $\beta 1$. In the case of G-CSF, STAT3 is recruited by C/ EBPs, requiring MAPK signaling. Our new findings 


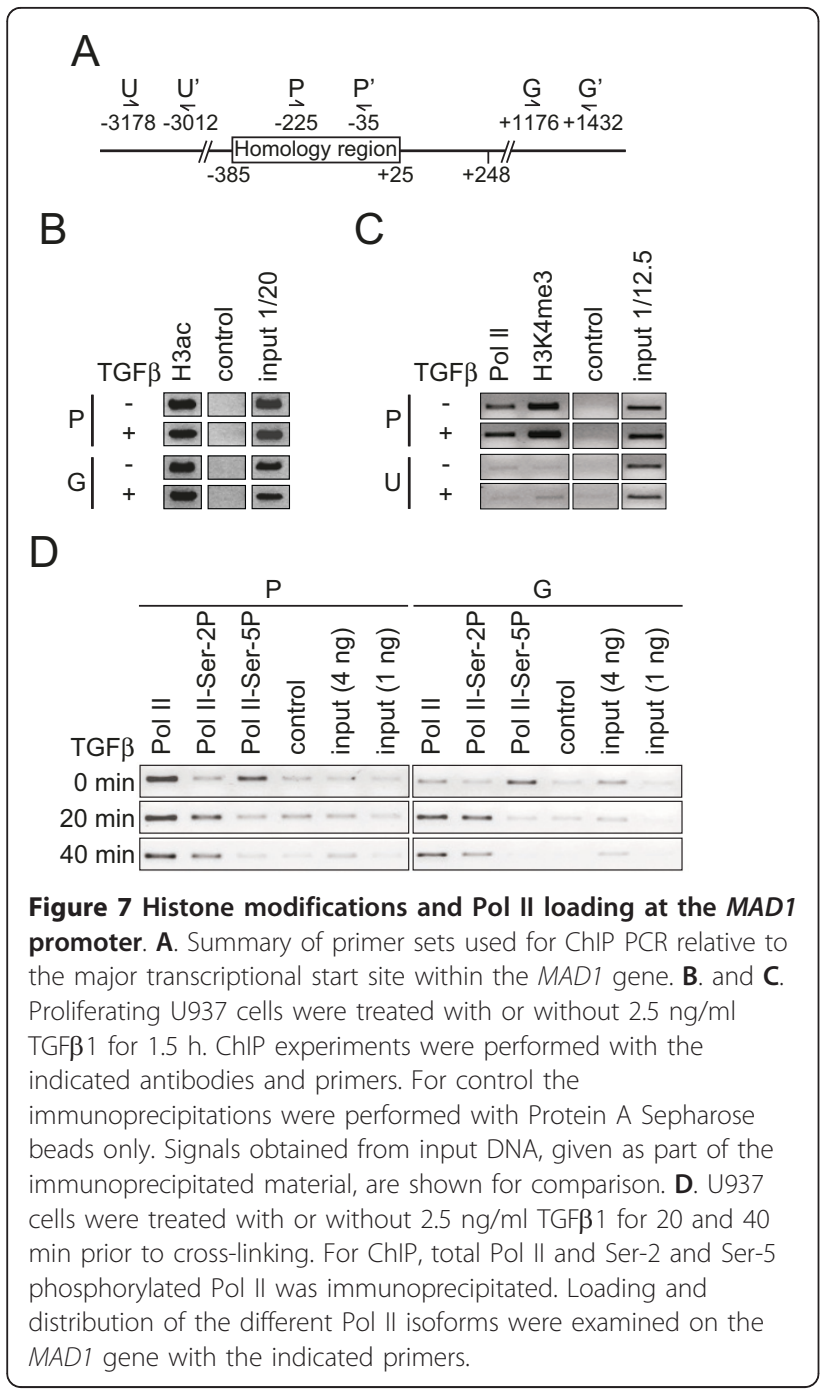

suggest that TGF $\beta 1$ signaling activates SMAD proteins and stimulates MAPK signaling. The activation of MAPK might be a common pathway that controls at least in part MAD1 expression. Consistent with this interpretation, SMAD3 cooperated with C/EBP proteins to activate $M A D 1$ promoter reporter genes. The finding that SMAD3 was bound to the MAD1 promoter suggests that SMAD3 is directly recruited to the MAD1 promoter by binding to C/EBPs or C/EBP associated factors. Because the GC box was also relevant, we propose that a large transcription factor/cofactor complex interacts with the identified promoter proximal region, including SMAD3. However, we point out that we cannot exclude direct binding of SMAD3 to the MAD1 promoter. Although no obvious binding sites could be detected, SMAD binding sites are rather short and leave the possibility open that SMAD3 forms a dimeric or multimeric complex with other factors, in which SMAD3 might bind directly to DNA.
The signals that are integrated at the proximal MAD1 promoter translate into the activation of Pol II as measured by its progression into the gene body and the concomitant change in the phosphorylation of the C-terminal domain of Pol II. This is consistent with recent observations on many genes, which have provided evidence that Pol II phosphorylated at Ser-5 is located at the promoter in a preactivated or paused mode. The switch to Ser-2 phosphorylation, possibly by the recruitment and activation of the P-TEFb kinase CDK9, results in the activation and promoter clearance of Pol II [34]. Thus this represents a situation as it is now becoming evident at many different promoters that are being studied in detail. It is worth noting that Pol II was found to be associated with the MAD1 promoter prior to stimulation with cytokines. Thus at least in U937 tumor cells, the MAD1 promoter is preoccupied by Pol II and thus allows for rapid activation by multiple signals. It will now be of interest to specifically dissect how different cytokines use the C/EBP-SP transcription factor platform to activate the paused Pol II.

\section{Methods}

\section{Reporter gene construct and expression vectors}

The cloning of $M A D 1$ promoter reporter gene constructs has been reported previously [17]. Descriptions of pEQ176-ß-galactosidase, $\mathrm{pCB6}{ }^{+}-\mathrm{C} / \mathrm{EBP} \alpha$, and $\mathrm{pCB6}{ }^{+}-$ C/EBP $\beta$ are found in $[28,35]$; pCDNA3+-C/EBP $\varepsilon$ was obtained from A. Friedman [36]; pCL-neo-HA-SP1 and pCI-neo-HA-SP1-N (a dominant negative form of SP1) were provided by $\mathrm{H}$. Rotheneder [37].

\section{Cell culture and treatment}

HEK293 (ATCC CRL-1573) and HeLa (ATCC CCL-2) cells were cultured in DMEM (Gibco) with $10 \%$ fetal calf serum (Gibco) and penicillin/streptomycin (Seromed). U937 (ATCC CRL-1593.2) promyelocytes were grown in RPMI 1640 (Gibco) with 10\% fetal calf serum and penicillin/streptomycin. All cells were cultured at $37^{\circ} \mathrm{C}$ and $5 \% \mathrm{CO}_{2}$. U937 cells were treated with TGF $\beta 1$ (Peprotec) at a concentration of $2.5 \mathrm{ng} / \mathrm{ml}$ and with $5 \mu \mathrm{M}$ SB505124 (Sigma-Aldrich) as indicated. Proliferation and viability of U937 cells were analyzed using Trypan Blue staining and the CASY cell counting system (Innovatis).

\section{Transient transfection and luciferase assay}

Transient transfection of HEK293 and HeLa cells were performed using the calcium phosphate co-precipitation method as described previously [38]. HeLa cell cotransfected with pSuper-sh-C/EBP $\beta$ were harvested 72 hours post-transfection. For luciferase assays HeLa cells were co-transfected overnight with a total amount of 3$5 \mu \mathrm{g}$ plasmid DNA and cultured for $48 \mathrm{hrs}$ under 
normal growth conditions prior to harvesting. Luciferase activity was measured using a bioluminator (ELISAReader Victor2). The relative luciferase activity was normalized to the $\beta$-galactosidase activity. All experiments were performed in duplicates or triplicates with at least three independent replicates.

The online program siDirect (genomics.jp/sidirect) was used to design shRNA oligonucleotides targeting the $C / E B P \beta$ mRNA and the resulting sequences were analyzed via the BLAST algorithm. The hybridized oligonucleotides were cloned into the pSuper vector (obtained from R. Bernards) linearised with $B g l \mathrm{II}$ and HindIII [39].

Sense: 5'GATCCCCAGCACAGCGACGAGTACAATCTTCAAGAGAGATTGTACTCGTCGCTGTGCTTT TTTGGAAA;

Antisense: 5'AGCTTTTCCAAAAAAGCACAGCGACGAGTACAATCTCTCTTGAAGATT GTACTCGTCGCTGTGCTGGG.

\section{RNA preparation and quantitative RT-PCR}

The RNAeasy Mini Kit (Qiagen) was used for total RNA extraction, according to the manufacturer's instruction and residual genomic DNA was removed by DNase (Qiagen) digestion. $1 \mu \mathrm{g}$ total RNA was reverse transcribed into cDNA using the Transcriptor First Strand cDNA Synthesis Kit (Roche) and analyzed by quantitative real time PCR using a LightCycler (Roche). The real time PCR reactions were performed with the SYBRgreen Ready Mix (Qiagen) and the following primer pairs: $M A D 1$ QantiTect primer assay (Qiagen) and $\beta$-GLUCURONIDASE-f 5'-CTCATTTGGAATTTTGCCGATT3', $\beta$-GLUCURONIDASE-r 5'-CCGAGTGAAGATCC CCTTTTTA-3'. The relative quantification of MAD1 mRNA was calculated by the comparative CT method and normalized to $\beta$-GLUCURONIDASE using the Software RelQuant.

\section{Chromatin immunoprecipitation (ChIP) assay and RE-ChIP assay}

ChIP assays were performed as described previously [9]. U937 cells were grown in a spinner flask to a maximal density of $10^{6}$ cells $/ \mathrm{ml}$. Following TGF $\beta 1$ treatment 5$2.5 \times 10^{7}$ cells $/ \mathrm{ml}$ per IP were harvested. For immunoprecipitation $2 \mu \mathrm{g}$ of the following antibodies were used: H3ac (06-599, Upstate); H3K4me3 (8580-50, Abcam); Pol II N20 (SC-899, Santa Cruz Biotechnology); Pol II CTD phosphoserine 2 H5 (MMS-129R, Covance); Pol II CTD phosphoserine 5 H14 (MMS-134R, Covance), C/ EBPa 14AA (SC-61, Santa Cruz Biotechnology); C/EBP $\beta$ C19 (SC-150, Santa Cruz Biotechnology), SP1 PEP2 (SC-59, Santa Cruz Biotechnology), SP1 (07-124, Upstate), Cytochrome C (SC-7159, Santa Cruz Biotechnology), SMAD3 (ab28379 Abcam). In addition SP1- specific antibodies were obtained from G. Suske [40]. The following primer pairs were used for PCR analysis of the MAD1 gene:

U: 5'CCTCTTAATATACTGTCCTATGC-3';

U': 5'GTCACAGCTCTCCAGAAATAGAAG-3';

P: 5'AGTTGCGAATCCTGTCACCA-3';

P': 5'TTCTCTTGACAGGCCAGCTT-3';

G: 5'-ATATTGTAGGTGACACAAACTGC-3';

G': 5'-ATCTCACTTGAAGCTTCCACAG-3'

MYOD1: 5'-CCGCCGCTTTCCTTAACCACAAAT-3'

MYOD1': 5'-GTAGATAGCAAAGTGCTGGCAGTC-3'

For Re-ChIP assays the first immunoprecipitation was performed as above. Then the samples were washed once in ChIP RIPA buffer $(150 \mathrm{mM} \mathrm{NaCl}, 10 \mathrm{mM}$ Tris$\mathrm{HCl} \mathrm{pH} 7.5,1 \mathrm{mM}$ EDTA, 1\% NP40, 0.1\% DOC, 0.1\% SDS, $0.5 \%$ aprotinin) and the protein-DNA complexes solubilized in release buffer (1\% SDS, $10 \mathrm{mM}$ DTT, TEbuffer $\mathrm{pH}$ 7.5). The beads were incubated at $37^{\circ} \mathrm{C}$ for $30 \mathrm{~min}$. To the supernatant 4 volumes of RIPA-SDS $(150 \mathrm{mM} \mathrm{NaCl}, 10 \mathrm{mM}$ Tris pH 7.5, 1\% NP40, 1\% DOC, 0.5\% aprotinin, $1 \mathrm{mM}$ EDTA, $1 \mathrm{mM}$ iodoacetamid) were added to perform the second immunoprecipitation.

\section{Electrophoretic mobility shift assay (EMSA)}

The following oligonucleotides were $\gamma^{32}$ P-ATP radiolableled and used in EMSAs:

CCAAT-b1 f: 5'AGCCCTCTCCCAATCGCACAAG3'; CCAAT-b1 r: 5'CTTGTGCGATTGGGAGAGGGCT-3'; NE-CCAAT f: 5'-TCGAGATGGGGCAATAT-3';

NE-CCAAT r: 5'-ATATTGCCCCATCTCGA-3';

GC box1 f: 5'-AAGTGTAGGGGCGGGGCATTCT-3';

GC box1 r: 5'-AGAATGCCCCGCCCCTACACTT-3'.

HEK293 whole cell extracts were prepared on ice in Frackelton-lysis buffer (10 mM Tris-HCL pH 7.05, 50 $\mathrm{mM} \mathrm{NaCl}, 30 \mathrm{mM}$ Na4P2O7, $50 \mathrm{mM} \mathrm{NaF}, 5 \mu \mathrm{M}$ $\mathrm{ZnCl} 2,1 \%(\mathrm{v} / \mathrm{v})$ Triton X-100, 10\% (v/v) glycerol, 100 $\mu \mathrm{M}$ Na3VO4, $150 \mu \mathrm{M}$ benzamidin, $0.025 \mathrm{U} / \mathrm{ml}$ $\alpha$-macroglobulin, $2.5 \mu \mathrm{g} / \mathrm{ml}$ leupeptin, $14 \mu \mathrm{g} / \mathrm{ml}$ aprotinin). Whole cell extracts were incubated with the radiolabeled oligonucleotides at $30^{\circ} \mathrm{C}$ for $30 \mathrm{~min}$ and then subjected to electrophoresis as described previously [41]. In brief, for supershift assays antibodies or equivalent amounts of control antibodies or BSA were added and incubated on ice for $10 \mathrm{~min}$, prior to oligonucleotide addition. The protein-DNA complexes were separated on a $4.5 \%$ polyacrylamide gel containing $7.5 \%$ glycerol in 0.25 -fold TBE $(20 \mathrm{mM}$ Tris base, $20 \mathrm{mM}$ boric acid, 0.5 $\mathrm{mM}$ EDTA, $\mathrm{pH}$ 8) at $20 \mathrm{~V} / \mathrm{cm}$ for $4 \mathrm{~h}$. Gels were fixed in $10 \%$ methanol, $10 \%$ acetic acid, and $80 \%$ water for 1 $\mathrm{h}$, dried, and autoradiographed. The following antibodies were used in EMSAs: C/EBP $\alpha$ 14AA (SC-61, Santa Cruz Biotechnology); C/EBP $\beta$ C19 (SC-150, Santa Cruz Biotechnology); SP1 PEP2 (SC-59, Santa Cruz Biotechnology), SP1 (07-124, Upstate), SP3 D-20 (SC-644, Santa 
Cruz Biotechnology), Cytochrom C (SC-7159, Santa Cruz Biotechnology).

\section{Western blotting}

To generate highly concentrated U937 whole cell extracts (10 7 cells/preparation), U937 cells were lysed in $20-30 \mu \mathrm{l}$ FT Lysis buffer (600 mM KCL, $20 \mathrm{mM}$ Tris-Cl pH 7.8, $20 \%$ glycerol, $10 \mu \mathrm{g} / \mathrm{ml}$ leupeptin, $10 \mu \mathrm{g} / \mathrm{ml}$ pepstatin A, $14 \mu \mathrm{g} / \mathrm{ml}$, aprotinin, $0.4 \mathrm{mg} / \mathrm{ml}$, Pefabloc) by pipeting up and down as described previously [42]. The freeze-thaw cycles in liquid nitrogen were repeated five times. The thawed lysates were incubated with $250 \mathrm{U}$ Benzonase (Merck) at RT for $10 \mathrm{~min}$. Whole cell extracts were resolved by SDS-Page and transferred onto nitrocellulose membranes, probed with MAD1 C19 (SC-222, Santa Cruz Biotechnology), $\alpha$-Tubulin (B-5-1-2, T-5168, Sigma), or C/EBP $\beta$ C19 (SC-150, Santa Cruz Biotechnology) antibodies followed by horseradish peroxidase (HRP)-labeled secondary antibody. Detection was performed with the either chemiluminescence ECL kit (Pierce) or SuperSignal West Femto Maximum Sensitivity Substrate (Pierce).

\section{List of abbreviations}

C/EBP: CCAAT-enhancer-binding protein; ChIP: Chromatin immunoprecipitation; CTD: Carboxy-terminal domain; DMSO: Dimethyl sulfoxide; EMSA: Electrophoretic mobility shift assay; G-CSF: Granulocyte colony stimulationg factor; H3ac: acetylated histone 3; H3K4me3: trimethylated lysine 4 of histone 3; MAX: MYC-associated factor x; MYC: Myelocytomatosis viral oncogene; PTEN: Phosphatase and tensin homologue deleted on chromosome ten; Pol: Polymerase; Ser: Serine; SMAD3: Mothers against decapentaplegic homolog 3; SP: Specific protein; SPdn: Specific protein dominate negative; TGF: Transforming growth factor; TGFR: Transforming growth factor receptor; TPA:12-O-tetradecanoylphorbol-13acetat.

\section{Acknowledgements}

We thank R. Bernards, A. Friedman, H. Rotheneder, and G. Suske for providing reagents, K. Eckert, J. Lüscher-Firzlaff, and L.-G. Larsson for helpful discussions. This work was supported by the Deutsche

Forschungsgemeinschaft Grant SFB 542 projects B8 and C11 to BL.

\section{Author details \\ ${ }^{1}$ Institute of Biochemistry and Molecular Biology, Medical School, RWTH Aachen University, 52057 Aachen, Germany. ${ }^{2}$ Peter MacCallum Cancer Center, Growth Control and Differentiation Program, Laboratory of Growth Control, Melbourne, Australia. ${ }^{3}$ Laboratory of Cellular Oncology, Center for Cancer Research, National Cancer Institute, National Institutes of Health, Bethesda, MD, USA.}

\section{Authors' contributions}

$\mathrm{NH}$ and $\mathrm{BL}$ designed the experiments. $\mathrm{NH}, \mathrm{KJ}$, and $\mathrm{CC}$ performed the experiments. $\mathrm{NH}, \mathrm{CC}$, and $\mathrm{BL}$ evaluated the data and wrote the manuscript. All authors read and approved the final manuscript.

\section{Competing interests}

The authors declare that they have no competing interests.

Received: 10 September 2010 Accepted: 23 February 2011 Published: 23 February 2011

\section{References}

1. Luscher B: Function and regulation of the transcription factors of the Myc/Max/Mad network. Gene 2001, 277(1-2):1-14.
2. Henriksson M, Luscher B: Proteins of the Myc network: essential regulators of cell growth and differentiation. Adv Cancer Res 1996, 68:109-182.

3. Meyer N, Penn LZ: Reflecting on 25 years with MYC. Nat Rev Cancer 2008, 8(12):976-990.

4. Eilers M, Eisenman RN: Myc's broad reach. Genes Dev 2008, 22(20):2755-2766.

5. Rottmann S, Luscher B: The mad side of the Max network: antagonizing the function of Myc and more. Curr Top Microbiol Immunol 2006, 302:63-122.

6. Foley KP, McArthur GA, Queva C, Hurlin PJ, Soriano P, Eisenman RN: Targeted disruption of the MYC antagonist MAD1 inhibits cell cycle exit during granulocyte differentiation. Embo J 1998, 17(3):774-785.

7. Gehring S, Rottmann S, Menkel AR, Mertsching J, Krippner-Heidenreich A, Luscher B: Inhibition of proliferation and apoptosis by the transcriptional repressor Mad1. Repression of Fas-induced caspase-8 activation. J Biol Chem 2000, 275(14):10413-10420.

8. Rottmann S, Speckgens S, Luscher-Firzlaff J, Luscher B: Inhibition of apoptosis by MAD1 is mediated by repression of the PTEN tumor suppressor gene. FASEB J 2008, 22(4):1124-1134.

9. Bouchard C, Dittrich O, Kiermaier A, Dohmann K, Menkel A, Eilers M, Luscher B: Regulation of cyclin D2 gene expression by the Myc/Max/Mad network: Myc-dependent TRRAP recruitment and histone acetylation at the cyclin D2 promoter. Genes Dev 2001, 15(16):2042-2047.

10. Hassig CA, Fleischer TC, Billin AN, Schreiber SL, Ayer DE: Histone deacetylase activity is required for full transcriptional repression by mSin3A. Cell 1997, 89(3):341-347.

11. Laherty CD, Yang WM, Sun JM, Davie JR, Seto E, Eisenman RN: Histone deacetylases associated with the $\mathrm{mSin} 3$ corepressor mediate mad transcriptional repression. Cell 1997, 89(3):349-356.

12. Sommer A, Hilfenhaus S, Menkel A, Kremmer E, Seiser C, Loidl P, Luscher B: Cell growth inhibition by the Mad/Max complex through recruitment of histone deacetylase activity. Curr Biol 1997, 7(6):357-365.

13. Cultraro CM, Bino T, Segal S: Function of the C-Myc antagonist Mad1 during a molecular switch from proliferation to differentiation. Mol Cell Biol 1997, 17(5):2353-2359.

14. Holzel M, Kohlhuber F, Schlosser I, Holzel D, Luscher B, Eick D: Myc/Max/ Mad regulate the frequency but not the duration of productive cell cycles. EMBO Rep 2001, 2(12):1125-1132.

15. Pulverer B, Sommer A, McArthur GA, Eisenman RN, Luscher B: Analysis of Myc/Max/Mad network members in adipogenesis: inhibition of the proliferative burst and differentiation by ectopically expressed Mad1. J Cell Physiol 2000, 183(3):399-410.

16. Ayer DE, Eisenman RN: A switch from Myc:Max to Mad:Max heterocomplexes accompanies monocyte/macrophage differentiation. Genes Dev 1993, 7(11):2110-2119.

17. Jiang K, Hein N, Eckert K, Luscher-Firzlaff J, Luscher B: Regulation of the MAD1 promoter by G-CSF. Nucleic Acids Res 2008, 36(5):1517-1531.

18. Larsson LG, Pettersson M, Oberg F, Nilsson K, Luscher B: Expression of mad, mxi1, max and c-myc during induced differentiation of hematopoietic cells: opposite regulation of mad and c-myc. Oncogene 1994, 9(4):1247-1252

19. Werner S, Beer HD, Mauch C, Luscher B, Werner S: The Mad1 transcription factor is a novel target of activin and TGF-beta action in keratinocytes: possible role of Mad1 in wound repair and psoriasis. Oncogene 2001, 20(51):7494-7504.

20. Wu S, Hultquist A, Hydbring P, Cetinkaya C, Oberg F, Larsson LG: TGF-beta enforces senescence in Myc-transformed hematopoietic tumor cells through induction of Mad1 and repression of Myc activity. Exp Cell Res 2009, 315(18):3099-3111.

21. Heldin CH, Landstrom M, Moustakas A: Mechanism of TGF-beta signaling to growth arrest, apoptosis, and epithelial-mesenchymal transition. Curr Opin Cell Biol 2009, 21(2):166-176.

22. Massague J: TGFbeta in Cancer. Cell 2008, 134(2):215-230.

23. Derynck $R$, Akhurst RJ: Differentiation plasticity regulated by TGF-beta family proteins in development and disease. Nat Cell Biol 2007, 9(9):1000-1004.

24. Moustakas A, Heldin $\mathrm{CH}$ : The regulation of TGFbeta signal transduction. Development 2009, 136(22):3699-3714

25. Zhang YE: Non-Smad pathways in TGF-beta signaling. Cell Res 2009, 19(1):128-139. 
26. Descargues P, Sil AK, Sano Y, Korchynskyi O, Han G, Owens P, Wang XJ, Karin M: IKKalpha is a critical coregulator of a Smad4-independent TGFbeta-Smad2/3 signaling pathway that controls keratinocyte differentiation. Proc Natl Acad Sci USA 2008, 105(7):2487-2492.

27. Nerlov C: C/EBPs: recipients of extracellular signals through proteome modulation. Curr Opin Cell Biol 2008, 20(2):180-185.

28. Oelgeschlager M, Nuchprayoon I, Luscher B, Friedman AD: C/EBP, c-Myb, and PU.1 cooperate to regulate the neutrophil elastase promoter. $\mathrm{Mol}$ Cell Biol 1996, 16(9):4717-4725.

29. Margaritis T, Holstege FC: Poised RNA polymerase II gives pause for thought. Cell 2008, 133(4):581-584.

30. Guenther MG, Levine SS, Boyer LA, Jaenisch R, Young RA: A chromatin landmark and transcription initiation at most promoters in human cells. Cell 2007, 130(1):77-88.

31. Price DH: Poised polymerases: on your mark...get set...go! Mol Cell 2008, 30(1):7-10.

32. Sims RJ, Belotserkovskaya R, Reinberg D: Elongation by RNA polymerase II: the short and long of it. Genes Dev 2004, 18(20):2437-2468.

33. Saunders A, Core LJ, Lis JT: Breaking barriers to transcription elongation. Nat Rev Mol Cell Biol 2006, 7(8):557-567.

34. Weake VM, Workman JL: Inducible gene expression: diverse regulatory mechanisms. Nat Rev Genet 2010, 11(6):426-437.

35. Firzlaff JM, Luscher B, Eisenman RN: Negative charge at the casein kinase II phosphorylation site is important for transformation but not for $\mathrm{Rb}$ protein binding by the E7 protein of human papillomavirus type 16 . Proc Natl Acad Sci USA 1991, 88(12):5187-5191.

36. Verbeek W, Gombart AF, Chumakov AM, Muller C, Friedman AD, Koeffler HP: C/EBPepsilon directly interacts with the DNA binding domain of c-myb and cooperatively activates transcription of myeloid promoters. Blood 1999, 93(10):3327-3337.

37. Rotheneder H, Geymayer S, Haidweger E: Transcription factors of the Sp1 family: interaction with $\mathrm{E} 2 \mathrm{~F}$ and regulation of the murine thymidine kinase promoter. J Mol Biol 1999, 293(5):1005-1015.

38. Bousset $\mathrm{K}$, Oelgeschlager $\mathrm{MH}$, Henriksson M, Schreek S, Burkhardt $\mathrm{H}$, Litchfield DW, Luscher-Firzlaff JM, Luscher B: Regulation of transcription factors c-Myc, Max, and c-Myb by casein kinase II. Cell Mol Biol Res 1994, 40(5-6):501-511.

39. Brummelkamp TR, Bernards R, Agami R: A system for stable expression of short interfering RNAs in mammalian cells. Science 2002, 296(5567):550-553.

40. Hagen G, Muller S, Beato M, Suske G: Sp1-mediated transcriptional activation is repressed by Sp3. EMBO J 1994, 13(16):3843-3851.

41. Oelgeschlager $M$, Janknecht $R$, Krieg J, Schreek S, Luscher B: Interaction of the co-activator CBP with Myb proteins: effects on Myb-specific transactivation and on the cooperativity with NF-M. Embo J 1996, 15(11):2771-2780.

42. Rudolph KL, Chang S, Lee HW, Blasco M, Gottlieb GJ, Greider C, DePinho RA: Longevity, stress response, and cancer in aging telomerasedeficient mice. Cell 1999, 96(5):701-712

doi:10.1186/1471-2199-12-9

Cite this article as: Hein et al:: TGF $\beta 1$ enhances MAD1 expression and stimulates promoter-bound Pol II phosphorylation: basic functions of C/ EBP, SP and SMAD3 transcription factors. BMC Molecular Biology 2011 $12: 9$.

\section{Submit your next manuscript to BioMed Central and take full advantage of:}

- Convenient online submission

- Thorough peer review

- No space constraints or color figure charges

- Immediate publication on acceptance

- Inclusion in PubMed, CAS, Scopus and Google Scholar

- Research which is freely available for redistribution 